\title{
ECL 12,1-7 INTERPRETADO POR ABRAHAM IBN 'EZRA
}

MARIANO GÓMEZ ARANDA

CSIC. Madrid

El pasaje Ecl 12,1-7 ha sido objeto de múltiples interpretaciones a lo largo de los siglos, tanto en el mundo judío como en el mundo cristiano; sin embargo la opinión que ha gozado de mayor popularidad ha sido la que ha interpretado este pasaje de forma alegórica, referido a la decrepitud del hombre en la vejez y a su muerte '. Desde que esta interpretación alegórica apareció en el Talmud y en los midrasión ${ }^{2}$ fue aceptada y transmitida por los comentaristas bíblicos como Raši, Ibn Gayat o Rašbam 3. Abraham ibn 'Ezra recoge también estas interpretaciones y otras de diversos comentaristas, algunos de ellos dificiles de identificar; en algunos casos parece aceptar la interpretación alegórica tradicional, pues no manifiesta ninguna objeción, pero en otros casos la rechaza completa-

1 Sobre las diversas interpretaciones que se han dado de este pasaje véase la amplia bibliografia citada en el artículo de F. A. SAWYER, "The Ruined House in Ecclesiastes 12: A Reconstruction of the Original Parable", JBL 94 (1975) 519-531.

${ }^{2}$ Vid. Śabb 151b-152a; QohR 12,1-7 y LevR 18,1.

${ }^{3}$ Para el comentario de Raši se ha seguido el texto que aparece en Biblia Rabbinica, A Reprint of the 1525 Venice Edition, Edited by Jacob ben Hayim ibn Adoniya, Introduction by Moshe Goshen-Gottstein, Jerusalem 1972, págs. 300-328. El comentario de Ibn Gayat fue atribuido a Saadia Gaon y editado por Y. QAFIAH, חמש מגילות ... עם פירושים עתיקים חיוצאים לאור פעם ראשונח על פי כתבי יד בצירוף מבואות חערות וחארות מאת..., Jerusalem 1962, págs. 161-296; su verdadera autoría fue

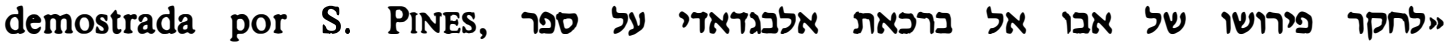
"198-213 y por G. VAJDA, "Quelques observations en marge du commentaire d'Isaac Ibn Ghiyath sur l'Ecclésiaste", The Seventy-Fifth Anniversary Volume of the Jewish Quarterly Review, Philadelphia 1967, 518-527. Un estudio sobre el comentario de Ibn Gayat a este pasaje aparece en $G$. VAJDA, «Ecclésiaste XII,2-7 interprété par un auteur juif d'Andalousie du XIe siècle», JSS 27 (1982) 33-46. El comentario de Rasbam ha sido editado y traducido por S. JAPHET and R. B. SALTERS, The Commentary of $R$. Samuel ben Meir Rashbam on Qohelet, Jerusalem-Leiden 1985. 
mente y ofrece su propio punto de vista. Para establecer un nuevo significado alegórico de algunos términos, utiliza todos sus conocimientos gramaticales y exegéticos 4 .

La interpretación alegórica tradicional consideraba "los días de la desgracia» (Ecl 12,1) referido a los días de la vejez y aconsejaba al hombre que recordara a Dios en la juventud, antes de llegar a la ancianidad '. Ibn 'Ezra acepta esta opinión pero añade que también se refiere a los días de aquella enfermedad que provoca la muerte del enfermo.

A partir del segundo versículo la interpretación alegórica tradicional identificaba el texto bíblico con las partes del cuerpo del anciano que se debilitaban con la edad. Según esta interpretación, "volverán las nubes después del aguacero" es una alegoría del llanto del anciano que hace que la vista se pierda poco a poco ${ }^{6}$. Ibn 'Ezra menciona esta opinión, pero interpreta «el sol, la luz, la luna y las estrellas» literalmente, explicando que la "luz» es "la luz del alba» y que el versículo es una metáfora de la situación del enfermo en el momento de la muerte:

«se le oscurece el mundo y le parece como si las nubes ocultaran la luz».

En el tercer versículo Ibn 'Ezra menciona la interpretación tradicional que identifica "los guardianes de la casa" con las caderas y las costillas, "los hombres fuertes» con las piernas, "las que muelen» con los dientes y "las que ven por las ventanas» con los ojos?. Ibn 'Ezra acepta esta opinión excepto en el primer caso, pues, según él, «los guardianes de la casa» son

«las manos con los brazos, que son los que guardan el cuerpo para que no le pase nada malom.

\footnotetext{
${ }^{4}$ Para el comentario de Ibn 'Ezra me he basado en el texto de la edición crítica que estoy realizando a partir de los manuscritos que contienen esta obra.

${ }^{5}$ Vid. Šabb 15b; QohR 12,1; LevR 18,1. También siguen esta opinión: Raši, vid. Peruš, ibid.; Rašbam, vid. S. JAPHET and R. B. SALTERS, op. cit., págs. 206-207; Ibn Gayat, vid. Y. QAfiah, op. cit., pág. 283 y Saadia Gaon, vid. S. RosenblatT, Saadia Gaon. The Book of Beliefs and Opinions, New Haven 1976 (6th printing), págs. 386387.

${ }^{6}$ Vid. Sabb 151b; Raši acepta esta opinión, vid. Peruš, ibid., que aparece citada también por Ibn Gayat, vid. Y. QAFIAH, op. cit., pág. 288.

7 Así aparece en Sabb 152a; QohR 12,3; LevR 18,1 y es citada por Raši, vid. Perus', ibid., y Rašbam, vid. S. JAPHET and R. B. SALTERS, op. cit., págs. 208-209.
} 
Según esta interpretación al anciano o al enfermo le tiemblan los brazos y las manos, se le doblan las piernas, las muelas dejan de masticar y los ojos pierden la visión.

"Se cierren las puertas en el mercado" $(\mathrm{Ecl} 12,4)$ fue interpretado en el Talmud y en los midraším como "los orificios del hombre» ${ }^{8}$, pero Ibn "Ezra identifica "las puertas" con los labios, relacionando esta expresión con el versículo «las puertas de su rostro, ¿quién abrió?» $(\mathrm{Jb} 41,6){ }^{9}$. "Con el debilitamiento del ruido del molino" fue identificado por Ibn 'Ezra, siguiendo la interpretación alegórica, con la debilidad del estómago, "que es el que tritura la comida" ${ }^{10}$. Pero además interpreta la primera parte del versículo como una metáfora de las consecuencias de la debilidad del estómago para el anciano o el enfermo: cuando se debilita el ruido del molino quiere decir que deja de triturar el trigo, no hay harina y no se puede fabricar pan, entonces las panaderías del mercado permancen cerradas, como permanecen cerrados los labios del anciano o del enfermo, porque su estómago no puede digerir la comida.

En el comentario de la frase "y se levante el canto del pájaro» $($ Ecl 12,4$)$ Ibn 'Ezra se aparta de la interpretación alegórica y la explica en su sentido literal:

"la comida produce sueño y al cerrar la boca se corta la comida", pero el anciano o el enfermo «se despierta al sonar el canto".

Siguiendo la interpretación alegórica de las partes del cuerpo, nuestro autor identifica "y enmudezcan todas las hijas del canto" $($ Ecl 12,4) con

«la garganta, que anteriormente era la que cantaba, pero fue enmudeciendo su voz hasta que dejo de oirse».

En este caso las obras que explican el texto bíblico referido a las partes del cuerpo no recogen esta interpretación, a pesar de que resulta bastante fácil identificar, desde el punto de vista de la

${ }^{8}$ Vid. Šabb 152a; QohR 12,4; LevR 18,1; Raši, vid. Peruš, ibid., y Rašbam, vid. S. JAPHET and R. B. SALTERS, op. cit., págs. 208-209.

9 También Ibn Gayat, citando este mismo versículo, lo interpreta así; vid. Y. QAFIAH, op. cit., pág. 287.

10 Vid. Sabb 152a; QohR 12,4; LevR 18,1; también lo interpretan así: Rasi, vid. Perus, ibid., y Rašbam, vid. S. JAPHET and R. B. SALTERS, op. cit., págs. 208-209. También aparece en el comentario de Ibn Gayat, vid. Y. QAFIAH op. cit., pág. 287. 
alegoría, «las hijas del canto» con el órgano encargado de producir precisamente el canto.

Ibn 'Ezra menciona diversas interpretaciones a propósito del versículo 5: la primera de ellas es la que interpreta que los ancianos "de un lugar alto tienen miedo y hay temores en el camino" porque no tienen fuerza para subir. Esta interpretación aparece en el Talmud, donde los sabios explican que al anciano hasta la colina más pequeña le parece una montaña muy alta ", y es admitida por Raši ${ }^{12}$ y Rašbam ${ }^{13}$. Menciona también la opinión de los que interpretan que el I de רִרִאו es paragógico y que debe ir, por lo tanto, en singular ${ }^{14}$. Otros interpretan, según cita nuestro autor, que son las piernas del anciano las que tienen miedo; esta interpretación pretende, probablemente, justificar el uso del plural ירִאו. Ibn 'Ezra descarta que "un lugar alto" se refiera a una montaña o a una colina; según él, se refiere al espíritu del hombre que sabe que va a morir y siente miedo de subir a «un lugar elevado»; tiene miedo del camino que le llevará hasta el mundo divino, como dice el versículo: «hay temores en el camino".

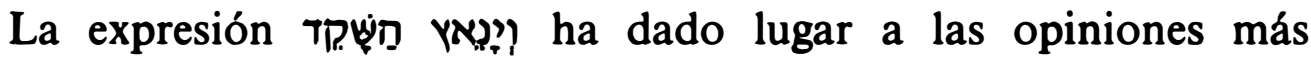
diversas; Ibn 'Ezra menciona la que interpreta 'florecer', considerando el $\kappa$ como un añadido, como «se levanta floreciente (נצج)" (Gen 40,10), y así se puede traducir como "florece el almendro" is y se refiere a que al viejo se le llena la cabeza de canas como el almendro se cubre de blanco cuando florece. Así lo interpreta el comentarista caraíta Salmon ben Yeruhim, citando el ejemplo de Gen 40,10 ${ }^{16}$, y es mencionada también esta opinión en el comentario de Ibn Gayat ${ }^{17}$. Otra interpretación que aparece en el comentario de Ibn 'Ezra explica que son

11 Vid. Šabb 152a.

12 Vid. Perus', ibid.

13 Vid. S. JAPHET and R. B. SALTERS, op. cit., págs. 208-209.

14 Así se propone en Biblia Hebraica Stuttgartensia, ... ediderunt K. Elliger et W. RudolPh, Textum Masoreticum curavit H. P. RUGER, Masoram elaboravit G. E. WeIL, Stuttgart 1977, sub loco.

15 Esta es la traducción que se propone en F. CANTERA Burgos - M. Iglesias GonZÁlez, Sagrada Biblia, Madrid 1979, pág. 771.

16 Vid. G. VAJDA, Deux commentaires karaltes sur l'Ecclésiaste, Leiden 1971, págs. 41, 222-223.

17 Vid. Y. QAFIAH, op. cit., pág. 288. 
"las canas que vienen después de las canas de la cabeza y son la barba».

La propia interpretación de Ibn 'Ezra está basada en las reglas

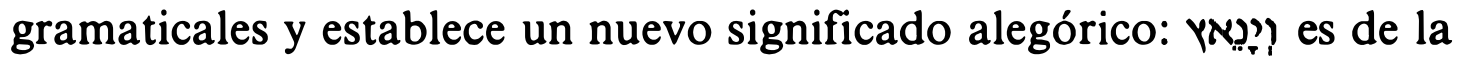
raíz נֵֵַ 'rechazar'; שִִׁ es un adjetivo, según el paradigma de 'fértil' y 'abundante', de la raíz Tọ 'vigilar' y significa que el espíritu del hombre, que es el "vigilante" (שָד) del cuerpo, "rechaza vigilar", es decir, el espíritu no quiere seguir cuidando del cuerpo. La traducción del texto bíblico según este comentario es: «el vigilante desprecia».

A propósito de la expresión «la langosta se convierte en una carga", Ibn "Ezra dice que algunos interpretan "la langosta" como

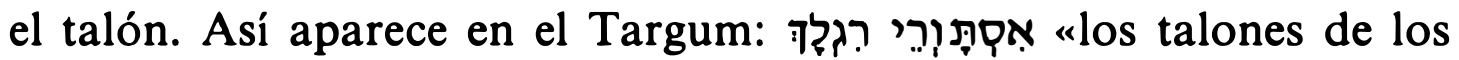
pies" ${ }^{18}$ y en los midrašum ${ }^{19}$. Otros lo interpretan como "las vergüenzas que le cuelgan hacia abajo"; Ibn Gayat menciona también esta opinión diciendo que algunos piensan que "el almendro" y "la langosta" son el pene y los testículos que se debilitan con la edad y al anciano le caen hacia abajo ${ }^{20}$. También cita Ibn 'Ezra a los que interpretaron חָגב 'langosta' cambiando el $n$ por ע; según esta inter-

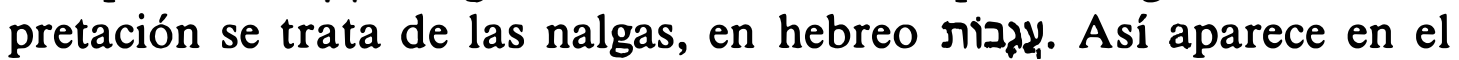
Talmud ${ }^{21}$, al que siguen Raši ${ }^{22}$ y Rašbam ${ }^{23}$. Ibn 'Ezra critica esta opinión porque, según él, las únicas letras que se pueden permutar son $\mathcal{K}, \mathrm{l}, \mathrm{n} \mathrm{y}$ '. El método del cambio de una consonante por otra para interpretar una palabra gozó de gran popularidad entre los exegetas judíos, pero Ibn 'Ezra aquí defiende que este método sólo se puede aplicar a las letras débiles mencionadas, porque son las únicas que unas veces aparecen y otras están ocultas ${ }^{24}$. Ibn 'Ezra interpreta esta frase en su sentido literal, pero refiriéndose al espíritu:

18 Vid. M. Jastrow, A Dictionary of the Targum, the Talmud Babli and Yerushalmi,

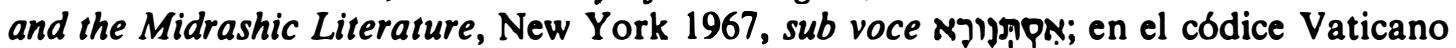
Urbinati I aparece vocalizado אורנור, vid. edición facsímil de E. LEVINE, The Targum to the Five Megillot, Jerusalem 1977, pág. 46 del texto arameo. En la edición de Sתבי חקדש בארמית, vol. IVa, Leiden 1968, pág. 167.

19 Vid. LevR 18,1 y QohR 12,5.

${ }^{20}$ Vid. Y. QAFIAH, op. cit., pág. 288.

21 Vid. Šabb 152a.

22 Vid. Peruš, ibid.

${ }^{23}$ Vid. S. JAPHET and R. B. SALTERS, op. cit., págs. 208-209.

${ }^{24}$ Sobre el uso de este método de interpretación exegética por parte de los gramáticos medievales, vid. A. SÁEnz-Badillos - J. TARgarona Borrás, Gramáticos hebreos de Al-Andalus (Siglos X-XII), Córdoba 1988, págs. 168 ss. 
"la langosta» es una carga pesada que tiene que soportar el vigilante, que es el espíritu. Mediante el argumento rabínico qal wa-homer ${ }^{25}$ nuestro autor explica que si "la langosta", que es una cosa de poca importancia ${ }^{26}$, "se convierte en una carga", con cuánta más razón lo será el cuerpo para el espíritu.

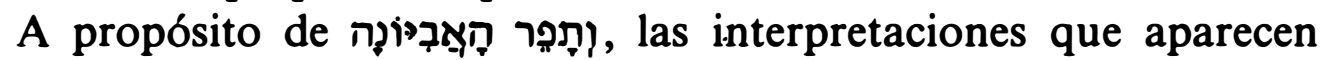
en el comentario de Ibn 'Ezra dan lugar a traducciones muy dife-

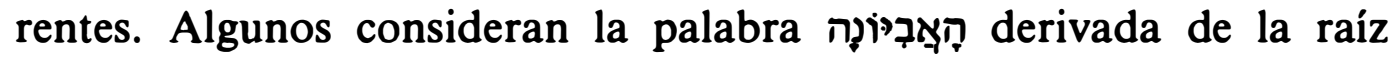
אָרָ 'desear' y significa para ellos que el deseo sexual desaparece con la edad; así se encuentra en los midraším y en los comentarios de Raši y Rašbam ${ }^{27}$. También cita nuestro autor la opinión de $R$. 'Adonim ben Tamim, uno de los sabios de Kairawan del s. X, que interpreta esta palabra como un diminutivo femenino del adjetivo אָבִיוֹ 'pobre' y dice que es un epíteto del espíritu del hombre; según esta interpretación se podría traducir como "la pobrecita». Ibn 'Ezra critica esta interpretación diciendo que en hebreo bíblico no existen diminutivos, porque

«si estuviera en las bases de la lengua hacer diminutivos, se encontrarían en la Biblia cientos y miles».

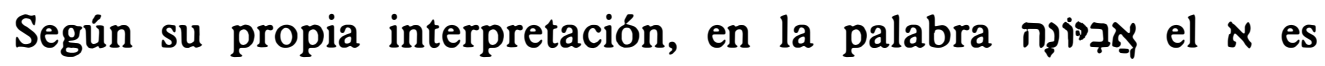
paragógico, como en otros casos de la Biblia ${ }^{28}$, y se trata del adjetivo מִברינה 'inteligente', que califica al espíritu: «el poseedor de la inteligencia". Sobre רภู), dice Ibn 'Ezra que se trata de un verbo transitivo de המפיר y significa que

${ }^{25}$ Conocido también con el nombre a fortiori; vid. A. NAVARro Peiro, "Las treinta y tres reglas de interpretación según el texto del Génesis ha-Gadol», Estudios Biblicos, XLVI (1988) 79-96, 83.

26 Ibn 'Ezra no dice nada sobre el significado de resto de los comentarios a los versículos en los que aparece esta palabra. En Num 13, 33 e Is 40, 22 se utiliza este término con el significado de 'langosta' para indicar algo que tiene poca importancia.

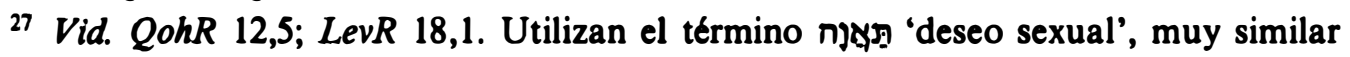

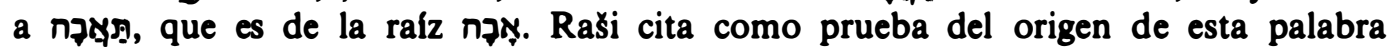
varios versículos en los que aparece la raíz אָרִ: «y no desearon (אבריתם) (Deut 1,26;

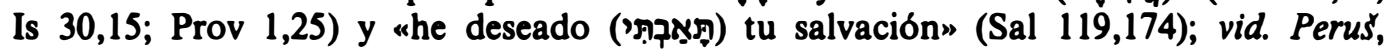
ibid. La interpretación de Rašbam también mantiene este sentido, vid. S. JAPHET and R. B. SAlTERS, op. cit., págs. 208-209.

${ }^{28}$ Ibn 'Ezra se basa aquí en la teoría de Yehuda Hayyuy que afirmaba que las letras débiles $\mathrm{N}, \mathrm{l}$, , y $n$ unas veces aparecían y otras se ocultaban, vid. A. SÁENZBadillos - J. Targarona Borrás, op. cit., págs. 95 ss. Según Ibn 'Ezra el $x$ no es de la raíz y no es necesario para entender el significado de la palabra. 
"el que aconseja, que es el espíritu, frustra [וֶף ] sus propios planes".

התפיר עִ עִצה 'deshacer una decisión' o 'frustar un consejo' (Is 8,10; Sal 33,10) ${ }^{29}$; La palabra מisis 'planes, decisiones' que utiliza Ibn 'Ezra es de la misma raíz que עִ 'consejo'. En mi opinión, lo que nuestro autor quiere decir es que en el momento de la muerte el espíritu deja de tomar decisiones sobre el cuerpo.

«Hacia su morada para siempre» es, según Ibn 'Ezra,

«la tumba, la casa en la que habitará para siempre»

y «dan vueltas por el mercado» quiere decir que cuando se llevan al muerto «lo cargan sobre los hombros y lo transportan» (Is 46,7).

El versículo 6, según la interpretación de Ibn 'Ezra, se puede traducir así: "Antes de que se desenganche la cuerda de plata, se rompa el cubo de oro, se quiebre el cántaro contra la fuente y corra la garrucha hacia el pozo". La explicación de nuestro autor es:

«el cubo está en un extremo de la garrucha, que gira con la cuerda, y un extremo de la cuerda está atado en el cubo; como está atada la cuerda, si se desengancha, no puede llegar hasta el agua. Cuando se rompa el cubo, corra la garrucha hacia el pozo y se rompa el cántaro, no puede subir el agua" ${ }^{30}$.

La interpretación alegórica tradicional explicaba este pasaje como la descomposición del cadáver después de la muerte; cada una de las partes mencionadas en este versículo se identificaban con las partes del cuerpo; Ibn 'Ezra no hace ninguna referencia a otras opiniones, pero su explicación está inspirada por la interpretación alegórica tradicional. Sin embargo, las partes del cuerpo que él

${ }^{29}$ Así en la traducción de F. CANTERA, op. cit., págs. 374 y 621.

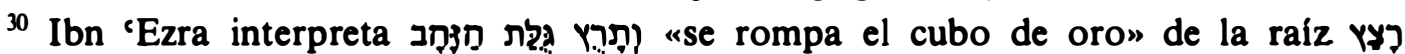

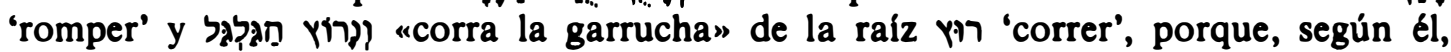
tiene el mismo paradigma que ככון que es de la raíz

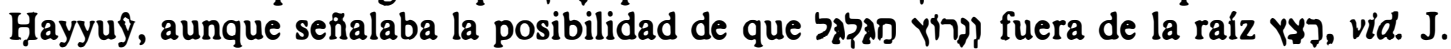
W. NUTT, Two Treatises on Verbs Containing Feeble and Double Letters by R. Jehuda Hayug of Fez, London-Berlin 1870, págs. 56, 117. También Yona Ibn Yaną̧ sugiere esta alternativa, vid. W. BACHER, Sepher Haschoraschim... von Abulwalld Merwan Ibn $\bar{G} a n a h$, Aus dem Arabischen in's Hebräische übersetz von Jehuda Ibn Tibbon, Berlin 1896, en la raíz ר. En la Biblia de Alba también se mantiene que es de la raíz yaר porque traduce "corra la rueda al pozo". 
menciona no coinciden en todos los casos con las que aparecen en el Talmud, en los midrašîm o en los comentaristas mencionados. En la interpretación de "la cuerda de plata» sí coincide con la interpretación tradicional: es la columna vertebral ${ }^{31} \mathrm{y}$, según él, se la denomina "de plata" porque es de color blanco. También tenían esta opinión Raši ${ }^{32}$ e Ibn Gayat ${ }^{33}$. «El çubo de oro» es el cerebro,

"y lo compara con el oro, por la membrana que lo cubre, que es roja".

También eran partidarios de esta interpretación Ibn Gayat ${ }^{34} \mathrm{y}$ Salmon ben Yeruhim ${ }^{35}$. "El cántaro» es la vejiga de la hiel, «la fuente» el hígado y "la garrucha» es el cráneo, que bajará al pozo - debajo de la tierra, es decir, a la tumba. Todas estas partes se descomponen en el momento de la muerte.

Explicando el versículo 7, dice nuestro autor que

«sólo quedan en el cuerpo los huesos»,

que son los que se convertirán en polvo, como dice el versículo "y volverá el polvo a la tierra», pero "el espíritu volverá a Dios». Aquí explica nuestro autor que el espíritu es "substancia», no «accidente», porque «un accidente no vuelve». El tema de la substancia y los accidentes, de claras connotaciones neoplatónicas, aparece con frecuencia en la filosofía de Ibn 'Ezra ${ }^{36}$.

En resumen, mediante estas interpretaciones Ibn 'Ezra ha querido demostrar que, en el momento de la muerte, el espíritu del hombre deja de realizar las funciones que tiene encomendadas sobre el cuerpo y, mientras éste se descompone en la tumba, el espíritu vuelve a Dios. Esta teoría aparece con frecuencia en su comentario al Eclesiastés, y es muy significativa en la introducción al comentario, donde explica que el cuerpo es la cárcel del espíritu y que éste,

${ }^{31}$ Vid. Šabb 15lb; QohR 12,6; LevR 18,1.

32 Vid. Perus, ibid.

33 Vid. Y. QAFIAH, op. cit., pág. 291.

34 Vid. ibid.

35 Vid. G. VAJdA, Deux commentaires, págs. 42-43, 223.

${ }^{36}$ Vid. D. Rosin, "Die Religionsphilosophie Abraham Ibn Esra's", MGWJ 42 (1898) 17-33, 58-73, 108-115, 154-161, 200-214, 241-252, 305-315, 345-362, 394-407, 444-457, 481-505; 43 (1899) 22-31, 75-91, 125-133, 168-184, 231-240. 


\section{mediante el desarrollo de la sabiduría, podrá descansar y disfrutar} después de la muerte cuando se separe del cuerpo.

\section{RESUMEN}

La interpretación alegórica de Ecl 12,1-7, que aparece en el Talmud, en los midrašim y en algunos comentarios bíblicos explica este pasaje como la decrepitud del hombre al final de su vida y la descomposición del cuerpo después de la muerte. Ibn 'Ezra adopta algunas de estas interpretaciones, pero, utilizando sus conocimientos exegéticos y las normas de la gramática hebrea, refleja la teoría neoplatónica, presente en otras obras suyas, de que el espíritu del hombre en el momento de la muerte deja de realizar sus funciones sobre el cuerpo y asciende hacia Dios, mientras el cuerpo se descompone en la tumba.

\section{SUMMARY}

The allegorical interpretation of Eccl 12:1-7, present in the Talmud and the midrastin, and accepted by some biblical commentators, was referred to the decrepitude of man in his old age and to the decomposition of his body after his death. Ibn 'Ezra takes some of these interpretations for his commentary, but, using his exegetical methods and the rules of the Hebrew grammar, he shows the neoplathonic theory about the spirit of man: the spirit abandons its functions in the body when the man dies, and it ascends to God as the body is disintegrating in the grave. 